Economia e Sociedade, Campinas, Unicamp. IE. http://dx.doi.org/10.1590/1982-3533.2020v30n1art05

\title{
Elementos de complexidade na economia do desenvolvimento de Furtado e Noyola *
}

\author{
André Roncaglia de Carvalho * \\ Fernanda Graziella Cardoso ${ }^{* * *}$
}

\begin{abstract}
Resumo
O artigo faz uma revisão do pensamento conjunto de Celso Furtado e Juan Noyola Vásquez desde uma perspectiva da abordagem da complexidade. Apresenta-se o esquema analítico dos autores, evidenciando a presença de elementos que remetem a mecanismos de retroalimentação que engendram propriedades emergentes do sistema econômico, tais como a baixa taxa de crescimento, o atraso tecnológico, a inflação persistente e o aprofundamento da desigualdade, contribuindo para a manutenção do resultado de armadilha do subdesenvolvimento.
\end{abstract}

Palavras-chave: Furtado, Celso, 1920-2004, Noyola Vásquez, Juan, 1922-1962, Abordagem da complexidade, Armadilha do subdesenvolvimento.

\section{Abstract \\ Complexity elements in Furtado and Noyola's development economics}

The paper reviews the joint contribution by Celso Furtado and Juan Noyola Vásquez from the perspective of the complexity approach. We present the analytical framework of both authors, highlighting the presence of feedback mechanisms within a dynamic interaction amongst social groups that engender emerging properties of the economic system, such as low economic growth, technological backwardness and persistent inflation, thereby contributing to the reinforcement of the "underdevelopment trap".

Keywords: Furtado, Celso, 1920-2004, Noyola Vásquez, Juan, 1922-1962, Complexity approach, Underdevelopment trap. JEL B22, B25, B31.

\section{Introdução}

O desenvolvimento, bem como o subdesenvolvimento, são resultado da dinâmica interativa de diversas variáveis, não somente relativas ao nível micro ou macroeconômico, mas que se relacionam também ao âmbito sociológico, cultural, político e ambiental. São, por isso, fenômenos (ou processos) complexos, cuja compreensão necessariamente extrapola o escopo da Economia. Porém, mesmo que a análise se restrinja somente ao escopo econômico, implica igualmente a necessidade de um aporte teórico-metodológico condizente com o caráter dinâmico, desequilibrado, imprevisível e, por conseguinte, complexo dos fenômenos relativos ao sistema econômico.

${ }^{*}$ Artigo recebido em 1 de fevereiro de 2018 e aprovado em 5 de fevereiro de 2020. Foi realizado com o apoio da Coordenação de Pessoal de Nível Superior - Brasil (Capes) - Código de Financiamento 001.

** Professor Adjunto do Departamento de Economia da Escola Paulista de Política, Economia e Negócios (EPPEN) da Universidade Federal de São Paulo (Unifesp), São Paulo, SP, Brasil. E-mail: andre.carvalho@unifesp.br. ORCiD: https://orcid.org/00000003-4873-3433.

*** Professora Adjunta dos Bacharelados em Ciências e Humanidades e em Ciências Econômicas, e do Programa de Pós-Graduação em Economia Política Mundial da Universidade Federal do ABC (UFABC), São Bernardo do Campo, SP, Brasil. E-mail: fernanda.cardoso@ufabc.edu.br. ORCiD: https://orcid.org/0000-0002-6868-8951. 
A história da complexidade na ciência econômica perfaz uma narrativa em que a "visão" corre à frente das ferramentas analíticas. Assim conclui Colander (2000, p. 11) na introdução do volume que avalia a história do pensamento econômico através das lentes da abordagem da complexidade. A transformação tecnológica que colocou a imensa capacidade de computação de dados no centro da produção científica abriria, alega o autor, amplas possibilidades de adotarmos estruturas analíticas mais complexas em substituição e/ou complementação ao que o método de simplificação estrutural foi capaz de iluminar nos planos físico e social.

A abordagem da complexidade vem demonstrando avanços significativos em anos recentes, a ponto de haver quem defenda estarmos vivendo uma era da complexidade ${ }^{1}$. Neste sentido, estendemos o escopo dos estudos organizados por Colander (2000) para incluir a indagação central que orienta o presente artigo, a saber: como a abordagem da complexidade pode enriquecer o nosso entendimento sobre o desenvolvimento econômico? Uma primeira aproximação a uma resposta desta magnitude requer necessariamente um recorte mais modesto do problema, para o qual há antecedentes na literatura econômica.

Foley (2003) enquadrou os economistas clássicos na abordagem da complexidade e também foi classificado por Rosser (2013) como um economista da complexidade. Este artigo segue a mesma linha e aplica o quadro (framing) da complexidade a dois autores da tradição cepalina, Juan Noyola Vázquez e Celso Furtado. Trata-se de um exercício de reconstrução histórica do pensamento destes autores - a partir de obras datadas, portanto -, na medida em que o quadro analítico aqui adotado sucede temporalmente seus escritos. Este expediente, no entanto, tem a vantagem de revelar traços significativos de uma teoria ou discurso que ficaram insuficientemente analisados porque avaliados segundo parâmetros incompatíveis com o objeto sob análise ${ }^{2}$. Contribuições teóricas alternativas encontravam-se, em alguma medida, sem um aparato metodológico capaz de contestar a abordagem mais convencional de economia (entendida aqui como o paradigma neoclássico) da qual destoavam; argumenta-se que a contribuição teórica desses dois autores, ambos relacionados à perspectiva estruturalista latino-americana, enquadra-se no que podemos convencionar como abordagem complexa do sistema econômico.

Furtado e Noyola se debruçaram sobre as dificuldades específicas que a periferia do sistema capitalista enfrentava para romper com a armadilha histórica do subdesenvolvimento ${ }^{3}$. E, conforme a tradição cepalino-estruturalista inaugurada pelo Manifesto Latino-Americano (Prebisch, 1949), recorreram a recursos analíticos alternativos à perspectiva derivada do laissez-faire - qual seja, de que não seriam necessárias intervenções deliberadas para direcionar o sistema nacional para uma trajetória virtuosa de crescimento e desenvolvimento, pois os mecanismos de mercado o fariam automaticamente. São esses recursos analíticos - causações circulares cumulativas, aprisionamento

(1) Ver Holt et al. (2011).

(2) Dow (2016, p. 161) aplica o conceito de framing ao mercado financeiro e explica em mais detalhes a metodologia, dizendo que: "Diferentes disciplinas enquadram o assunto de formas específicas, por exemplo. Mas, mesmo dentro das disciplinas, pode haver diferenças de enquadramento, que vão desde diferenças no significado de termos, através de diferenças teóricas, até diferenças nas recomendações de políticas (...) [Isso] envolve diferenças no significado de termos-chave, como "racionalidade" e "social”. (...) Mas o termo [framing] tem uma aplicação mais ampla para questões de conhecimento de forma mais geral, e, portanto, para o conhecimento dos analistas e dos analisados. Este é o uso mais comum do termo em sociologia” (Tradução nossa).

(3) Termo utilizado por Furtado (1992). Para mais detalhes, ver também Cardoso (2012). 
em resultados indesejáveis, etc. - que remetem à abordagem da complexidade e situam ambos os autores em campo analítico distinto de uma perspectiva dita etapista ${ }^{4}$ ou natural do processo de desenvolvimento, desde que fossem adotadas as instituições consideradas corretas. ${ }^{5}$

E, mais especificamente, nota-se convergência entre ambos no que se refere à interpretação sobre as causas e efeitos da inflação sobre o desenvolvimento econômico. Como mostraram Aprigio e Carvalho (2018), nota-se uma heterogeneidade nas abordagens cepalinas seminais em questões monetárias; Prebisch seguiria uma visão keynesiana padrão enquanto Furtado e Noyola fizeram inovações importantes, combinando a abordagem centro-periferia de Prebisch com forças estruturais e institucionais dinâmicas e complexas para explicar a "funcionalidade" da inflação para a reprodução do subdesenvolvimento, na medida em que a teoria convencional preconizava a adoção de políticas econômicas ortodoxas que reforçavam a armadilha do baixo crescimento e, portanto, da limitada transformação estrutural que, segundo os autores, caracterizava o desenvolvimento. Neste sentido, portanto, como mostrou Carvalho (2015, p. 54-63; 2019, p. 50-51), para ambos os autores a inflação resultava de uma estrutura produtiva "deformada". No entanto, Noyola explorou mais a fundo os determinantes da dinâmica inflacionária, enquanto Furtado se debruçou sobre a dinâmica produtiva e tecnológica associadas à inserção subordinada da periferia. Com efeito, a contribuição combinada dos autores oferece uma visão mais orgânica do subdesenvolvimento periférico.

O artigo está organizado em quatro seções, além desta introdução. A primeira faz uma breve introdução do problema da complexidade na história do pensamento econômico, de forma a situar historicamente as contribuições dos intelectuais latino-americanos vinculados à CEPAL. A segunda e a terceira seções enquadram, respectivamente, as contribuições de Noyola e Furtado na abordagem da complexidade, salientando os principais pontos que lhes permitem ser classificados como teóricos da complexidade no campo do desenvolvimento econômico. A quarta seção conclui com uma breve consolidação dos argumentos dentro do escopo da abordagem complexa do desenvolvimento econômico e aponta limitações e possíveis extensões do esquema analítico apresentado.

\section{Contribuições da abordagem da complexidade à economia do desenvolvimento}

A aplicação da Abordagem da Complexidade ao campo da Economia é ainda relativamente recente, o que lhe confere uma natureza ainda experimental, especialmente do ponto de vista da instrumentalização e formalização de seus modelos teóricos. No entanto, seu aporte teóricometodológico fornece substratos importantes para uma compreensão mais robusta dos problemas reais, inclusive daqueles relativos à temática do desenvolvimento. Na contramão da opção metodológica pela abstração e dedução e da busca pelo incremento da capacidade preditiva da teoria, a abordagem da complexidade aplicada à economia se propõe ao enfrentamento dos fenômenos complexos a partir da consideração da sua complexidade intrínseca - daí a maior aderência à realidade e a importância crucial da história, como resultado cumulativo temporal e espacialmente definido - e

(4) Por exemplo, a perspectiva de etapas do desenvolvimento como a de Rostow (1970).

(5) Sobre a adoção de instituições ditas corretas como condição suficiente para a geração do resultado de desenvolvimento, ver por exemplo a perspectiva de North (1990), para quem a adoção do receituário implícito ao Consenso de Washington seria o caminho a ser seguido. Tal perspectiva será alvo de crítica direta de autores como Chang (2002). 
da consideração da emergência de resultados em aberto - por isso, o foco não é o resultado, mas o entendimento do processo e, portanto, do incremento do poder explicativo da teoria.

A Abordagem da Complexidade tem como foco o estudo das interações de agentes heterogêneos, das quais resultam propriedades emergentes, cuja compreensão é crucial para o entendimento da dinâmica de funcionamento dos sistemas investigados. ${ }^{6}$ Contudo, há muitas conotações para o termo "complexidade", uma confusão comum em programas de pesquisa ainda não consolidados $^{7}$. São duas as abordagens principais em economia, a saber: a complexidade computacional (Velupillai, 2000; 2009) e a complexidade dinâmica (Rosser, 1999).

A primeira está associada à busca por soluções computáveis de sistemas complexos, baseados em uma série de premissas sobre a racionalidade dos agentes e como múltiplos equilíbrios, cicloslimites e processos explosivos emergem destas propriedades básicas. Por outro lado, a complexidade dinâmica está diretamente associada à sua não linearidade e, devido a processos endógenos de mudança, à possibilidade remota de que os processos de ajustamento conduzam o sistema a um ponto estável, ou a processos implosivos/explosivos, bem como a um ciclo-limite - como o de Goodwin (1951). É exatamente a vagueza desta definição que lhe propicia um maior grau de generalidade descritiva (Rosser, 2009). Uma característica importante dos sistemas não lineares dinâmicos é a sua sensibilidade às condições iniciais, pois as não linearidades fazem com que pequenas diferenças nas condições iniciais sejam ampliadas ao longo do tempo. Exemplificando, em termos de dotação de fatores das nações, a desigualdade tenderia a se ampliar, e não a ser atenuada. Essa é uma conclusão a que chegaram boa parte dos pioneiros do desenvolvimento (Cardoso, 2018). Myrdal (1957) define essa tendência como causação circular cumulativa. Em suas palavras:

Em geral uma transformação não provoca mudanças compensatórias, mas, antes, as que sustentam e conduzem o sistema, com mais intensidade, na mesma direção da mudança original. Em virtude dessa causação circular, o processo social tende a tornar-se acumulativo e, muitas vezes, a aumentar, aceleradamente, sua velocidade (Myrdal, 1957, p. 34).

Outra característica relacionada à não-linearidade típica de sistemas complexos é a dependência de trajetória, a qual implica que quaisquer mudanças na cadeia de eventos podem levar a um resultado muito diferente do que se esperaria antes de sua ocorrência. Essas duas características juntas fazem com que sistemas dinâmicos não lineares tenham resultados imprevisíveis - por isso a ideia de resultados em aberto. De outro modo, a linearidade está correlacionada com ordem, previsibilidade, causas e efeitos interligados, e leis universais que garantem alcance de resultados ditos desejáveis - ou seja, resultados de equilíbrio.

No sistema econômico, os processos e fenômenos complexos emergentes tem ao menos três causas principais, sendo as duas primeiras endógenas e a terceira exógena: o comportamento dos agentes (heterogêneos e dotados de racionalidade limitada), a estrutura institucional e fatores

(6) Para mais detalhes, vide Arthur (2015).

(7) Horgan (2015, n. 11, p. 648-649) compilou 45 tipos de complexidade, baseando-se numa lista que o físico Seth Lloyd, do MIT e do Santa Fe Institute compilou no início dos anos 1990. A principal crítica que se faz à abordagem da complexidade é a dificuldade da distinção com sistemas caóticos. Uma saída para esta indeterminação tem sido classificar complexidade como "quase-caos" ou "à beira do caos" (edge of chaos). Tais limitações não diminuem o valor da abordagem da complexidade aplicada aos processos sociais, a qual pode levantar importantes questões sobre as conclusões obtidas pelo paradigma dominante nas ciências sociais. Para mais detalhes, ver o capítulo 8 do livro de Horgan (2015). 
exógenos. O mainstream, por conta das restrições colocadas pelo seu método reducionista ou equilibrista, enfatizou desproporcionalmente a importância explicativa dos fatores exógenos, a partir dos denominados choques ${ }^{8}$. Partindo da hipótese de agente racional maximizador e norteado por análises de equilíbrio, as implicações dinâmicas da interação entre os agentes (do tipo representativo) e a estrutura institucional não importam, porque já se conhece o resultado final de antemão - qual seja, o de equilíbrio, garantido pelas hipóteses subjacentes ao método reducionista. Também como consequência, a macroeconomia pode ser derivada como simples agregação da microeconomia 9 .

A necessidade de combinar estudos históricos com uma análise macroeconômica microfundamentada evidencia-se na incrementada dificuldade de lidar com o tema do desenvolvimento socioeconômico, que envolve tanto a esfera micro - onde atuam os agentes e emergem as condições de concorrência - quanto a macroeconômica - em que se define a estrutura, representada pelas diversas instituições.

Resumidamente, o referido procedimento agregativo simplificado foi denominado de “cartesianismo reducionista" por Levins e Lewontin $(1985)^{10}$. Os autores defendem que esta postura metodológica é hostil a interconexões, permitindo apenas relações muito tênues entre diferentes partes da sociedade. Isso decorre de um modo analítico que requer a quebra de totalidades em partes e a delimitação, no âmbito destas, das propriedades essenciais do todo. É, por isso, a-histórico e "tecnicista", ignorando por completo a dimensão social.

O efeito mais profundo desta tradição de pensamento incide sobre a abordagem da evolução institucional, como bem aponta Setterfield (1993, p. 755), alegando que instituições são mais adequadamente tratadas "como fenômenos evolutivos, não-ótimos e que apresentam dependência de trajetória, em vez de em termos do historicismo simples ou da metáfora de equilíbrio padrão da teoria econômica dominante". A crítica de Setterfield adequa-se, por exemplo, às visões etapista (Rostow, 1974) ou da nova economia institucional (North, 1990) para as quais haveria um caminho institucional ótimo a ser seguido para se chegar ao desenvolvimento.

(8) Podemos seguir a definição de equilíbrio proposta por Kaldor (1933, p. 122): "Um equilíbrio determinado é um estado de repouso definido puramente em termos de dados exógenos ao sistema, que é alcançado independentemente do caminho seguido para ele" (Tradução nossa).

(9) Porém, conforme destaca Furtado (1967): "a microeconomia constitui um simples conjunto de regras de racionalidade formal e a macroeconomia, um esforço de captação a posteriori, e sua tradução em linguagem econômica, de um processo histórico no qual o "econômico" e o "não-econômico" se condicionaram mutuamente (...) O avanço da análise econômica requer a combinação desse duplo enfoque: por um lado o estudo dos processos históricos, ou das realidades sociais globais, e a construção de tipologias referidas aos mesmos; por outro, o aprofundamento na compreensão do comportamento dos agentes econômicos a partir de contextos perfeitamente definidos (...) Que seja necessário combiná-los indicada a complexidade do trabalho de teorização na ciência econômica" (Furtado, 1967, p. 85-86).

(10) Os autores relatam exaustivamente como esta abordagem foi rejeitada pela biologia em prol de uma abordagem sistêmica e a descrevem como se segue: "i) existe um conjunto natural de unidades ou partes que compõem qualquer sistema inteiro; ii) essas unidades são homogêneas em si mesmas, pelo menos na medida em que afetam a totalidade das quais são partes; iii) as partes são ontologicamente anteriores ao todo; isto é, as partes existem isoladamente e se juntam para fazer todo. As partes têm propriedades intrínsecas, que possuem isoladamente e que emprestam ao todo. Nos casos mais simples, o todo não é senão a soma de suas partes; casos mais complexos permitem interações das partes para produzir propriedades agregadas do todo; e iv) as causas são separadas dos efeitos, com as causas sendo propriedades de sujeitos e os efeitos, propriedades dos objetos. Embora as causas possam responder a informações provenientes de efeitos (chamados "circuitos de realimentação"), não há ambiguidade sobre o que está causando o sujeito e o que causa o objeto. (Esta distinção persiste em estatísticas como variáveis independentes e dependentes)” (Levins; Lewontin, 1985, p. 269. Tradução nossa). 
De acordo com Prado (2006), os sistemas econômicos devem ser encarados como composições globais, e não simplesmente como agregações. Deve-se adotar a perspectiva de um método sistêmico, uma mudança de enfoque que engrandeceria a importância explicativa do comportamento dos agentes do sistema e da sua estrutura institucional, pois a "interação dos indivíduos condicionada pela estrutura define o modo de composição do sistema, que, por sua vez, modifica em processo o comportamento dos indivíduos" (Prado, 2006, p. 310). Esta linha, o conceito de "auto-organização" merece destaque, pois trata de resultados que aparecem em um nível superior dentro dos limites de um sistema hierárquico dinâmico em decorrência de processos deflagrados em níveis mais baixos do sistema. Neste sentido, a dinâmica evolutiva das instituições se apoiaria em uma "complexidade hierárquica", a qual contempla a emergência de novas hierarquias em sistemas em processos evolucionários (Rosser; Rosser, 2017, p. 72).

Em se tratando da problemática do desenvolvimento socioeconômico, no contexto de um sistema político-econômico mundial com nações bastante heterogêneas apresentando diferentes graus de desenvolvimento que interagem entre si, a abordagem da complexidade certamente apresenta um elevado potencial para responder à indagação que vem desde pelo menos Adam Smith: afinal, qual é a origem da riqueza das nações? Por que, ao longo da história algumas nações se desenvolveram e outras não?

Beinhocker (2006) defende a equivalência da riqueza das nações ao conhecimento que estas acumularam e detêm, bem como ao grau de complexidade e ordenação que atingiram, como resultado do processo evolutivo pelo qual passaram, envolvendo a interação de variáveis sociais, estruturais, culturais e institucionais. Assim, as nações devem ser compreendidas como sistemas complexos adaptativos. Todas as nações, independentemente da sua condição socioeconômica em determinado momento, passaram por um longo processo de evolução. Badcock (2007) defende, por sua vez, que o desenvolvimento, sob a perspectiva da abordagem da complexidade, não tem nem começo, nem fim; é sempre inesperado e com seu resultado em aberto. Trata-se, portanto, de “[...] um lento processo de aproveitamento de possibilidades" (Rihani; Geyer, 2010, p. 45. Tradução nossa). Por isso também, não há uma lei ou caminho universal de desenvolvimento, pois, conforme dito anteriormente, cada país compôs (e compõe) seu próprio processo de evolução.

Assim, para que um sistema econômico nacional - adaptativo e complexo - possa incrementar suas possibilidades de existir e persistir em um estado de complexidade auto-organizada, com capacidade de prosseguir satisfatoriamente na trajetória evolutiva, refletida em seus resultados de desenvolvimento, ele deveria apresentar, como pré-requisito, ao menos elementos internos adequados (Cardoso, 2012) - dentre estes, enfatizamos a importância das instituições adequadas a tais fins definidos no processo de disputa política. Em alguma medida, a combinação de fatores internos poderia, potencialmente, possibilitar um melhor tratamento dos efeitos provocados pelos fatores externos e da interação deles com os próprios fatores internos.

Neste sentido, a abordagem da complexidade se alia ao antigo institucionalismo norteamericano (de natureza evolucionária), tomando-se como endógeno o processo de organização institucional, a partir da interação de indivíduos e grupos sociais no tempo histórico. Um arranjo institucional qualquer (que incorpora a prevalência de um aparato ideológico de suporte e perfis tecnológico e distributivo característicos) afeta os resultados sociais e econômicos, bem como a 
avaliação feita destes últimos; isto por sua vez determina o conjunto de escolhas disponíveis a famílias, empresas e governo, as quais afetarão o comportamento da atividade econômica. O desempenho econômico pode levar ao adensamento do arranjo institucional ou à sua contestação (dentro do espectro compreendido entre reformas e revoluções).

Estas observações são cruciais para a análise a ser desenvolvida a partir das contribuições de Noyola e Furtado: a relação entre instituições e os agentes sociais como fonte de explicações para a compreensão da "armadilha" histórica do subdesenvolvimento (Furtado, 1992). Arthur (1988, p. 13) definiu o conceito de "armadilha" (lock in) como uma situação de decisões sequenciais de agentes ou grupos que fazem emergir uma "vantagem" sistêmica persistente e, por isso, difícil de abandonar. Tal resultado deve necessariamente atender a algum critério de funcionalidade do sistema, de forma que, respeitada sua organização interna, haja um reforço positivo da situação. Setterfield (1993, p. 771, n. 14) qualifica historicamente este conceito para enfatizar a "armadilha das instituições ineficientes" (ou inefficient institutional lock-in), a saber:

Tais situações surgem como resultado de efeitos de dependência de frequência, ou seja, quando a frequência com que uma unidade social individual pratica um determinado comportamento (por exemplo, em conformidade com uma norma social ou costume) depende da frequência com que tenha sido praticada no passado e / ou a frequência com que é praticada por outras unidades sociais (Tradução nossa).

Neste sentido, a armadilha do subdesenvolvimento emerge como o resultado socialmente "indesejável" - ainda que politicamente viável - de um arranjo persistentemente ineficiente das instituições ${ }^{11}$. Noyola e Furtado consideram a interação de uma gama de forças sociais com diferenciadas posições no processo produtivo e no grau de acesso aos órgãos do Estado. A heterogeneidade destes grupos referente às dotações de recursos de poder, autonomia de ação e desigualdade material leva-os a rejeitar a noção de "política ótima" a ser executada por um "tecnocrata apolítico", baseada na noção ainda mais questionável de uma neutralidade científica da economia. Ademais, a ideia de uma "política ótima" requer necessariamente que se adote como universal a "visão de mundo" e o "posicionamento político" de um grupo particular do sistema. Tal expediente implicaria uma análise estática (sem dizer politicamente conservadora) das instituições, restringindo sensivelmente o escopo de análise do cientista social aos parâmetros institucionais e estruturais vigentes.

Por conta do efeito das retroalimentações positivas observadas em sistemas complexos adaptativos - e das suas propriedades derivadas, tais como dependência de trajetória e aprisionamento -, se não houver intervenção e redirecionamento, de modo a quebrar a lógica própria desses efeitos cumulativos, a tendência é que o hiato entre as nações desenvolvidas e as subdesenvolvidas aumente, assim como os hiatos internos, relativos às desigualdades entre as classes e entre as regiões de determinado sistema econômico nacional. Pois, quanto mais rica, poderosa, estruturada e tecnologicamente avançada for determinada nação, maior a sua capacidade intrínseca de continuar a

(11) Entendemos "ineficiência" aqui como a incongruência entre os meios institucionais adotados e os fins sociais pretendidos. 
ser assim; quanto mais pobre for a nação, menor a capacidade (de maneira exponencial) de superar tal condição ${ }^{12}$.

Realizadas essas breves considerações a partir da Abordagem da Complexidade aplicada ao desenvolvimento - destacando-se o resultado de armadilha de instituições ineficientes como uma das causas da armadilha do subdesenvolvimento - nas duas seções que seguem, recorre-se a dois pensadores da escola cepalino-estruturalista que apresentam elementos de complexidade que ajudam a compor a explicação dessas armadilhas.

\section{Noyola e a complexidade do subdesenvolvimento e da inflação}

O economista mexicano Juan Noyola Vázquez atuou na CEPAL durante a primeira década da existência desta instituição. Foi colega e importante interlocutor de Celso Furtado, com uma contribuição original à abordagem estruturalista da inflação, já fartamente documentada na literatura (Craven, 1994; Danby, 2005). A releitura de Noyola da perspectiva da complexidade pretende revelar que, para o autor, as instituições são processos evolucionários de longa memória (path-dependent) que desrespeitam a lógica de otimização como forma de superação de contradições e gargalos que se interpõem na marcha do desenvolvimento ${ }^{13}$.

A abordagem de Noyola combina essencialmente três conceitos: desequilíbrio social, contingência histórica e governo endógeno ao sistema (Danby, 2001, p. 17-18). Todos estes constituem senão facetas da mesma ideia subjacente, a saber: economia e política não podem ser reduzidas a instâncias uma da outra, de forma que a dinâmica econômica deve ser compreendida como resultado da disputa entre grupos de poder pelo controle do processo de mudança institucional.

Em outros termos, os móveis das ações de grupos e indivíduos transcendem o mero ganho pecuniário na pugna distributiva; tais motivos miram também o direcionamento da construção e da reforma das instituições de sorte a assegurar o comando do processo de mudança institucional bem como as políticas econômicas que garantirão tal primazia. Por este motivo, economia e política são

(12) Ainda mais recentemente, destaque-se a contribuição de Hausmann, Hidalgo et al. (2011) presente no Atlas da Complexidade, o qual permite relacionar a complexidade econômica com o grau de desenvolvimento. Os autores definem complexidade como: "Em última análise, a complexidade de uma economia está relacionada à multiplicidade de conhecimento útil incorporado nele. Para que uma sociedade complexa exista e se sustente, as pessoas que conhecem ferramentas como design, marketing, finanças, tecnologia, gestão de recursos humanos, operações e direito comercial devem ser capazes de interagir e combinar seus conhecimentos para criar produtos. Esses mesmos produtos não podem ser feitos em sociedades em que faltam frações desse conjunto de capacidades. A complexidade econômica, portanto, é expressa na composição da produção produtiva de um país e reflete as estruturas que emergem para reter e combinar conhecimento" (2011, p. 18. Tradução nossa).

(13) Noyola teve uma vida repleta de transformações intelectuais e profissionais finalizada precocemente por um acidente de avião enquanto atuava como economista no regime cubano no início dos anos 1960. Como é típico dos homens de ação do seu tempo, seu pensamento não pode ser desligado de questões pragmáticas relativas à dinâmica das coalizões políticas e seus efeitos sobre os resultados de políticas econômicas. Por isso, sua principal contribuição se circunscreve ao problema da inflação na América Latina, o principal problema assombrando os economistas em meados dos anos 1950. Mais do que isso, a questão inflacionária enseja o pretexto histórico para a aplicação do inovador quadro analítico de Noyola, cuja sofisticação encontra aplicação a variados problemas econômicos além daquele que lhe deu origem. Cumpre destacar, neste tocante, a concordância de Axel Leijonhufvud com a ideia de que inflações elevadas oferecem situações "atípicas ou patológicas" que revelam propriedades de um sistema complexo que ficariam encobertas se nos concentrássemos na análise de estados bem ordenados: "Em um campo não experimental, muitas vezes é uma boa estratégia de pesquisa prestar especial atenção às observações que fogem ao padrão. (...) Na macroeconomia, isso significa prestar especial atenção às grandes depressões, altas inflações e (agora) a transição do socialismo [ao capitalismo]" (1997, p. 322. Destaques adicionados e tradução nossa). 
indissociáveis neste quadro analítico. Noyola descreve um mecanismo de "procriação institucional", o qual resulta da propriedade de dependência de trajetória da evolução das instituições econômicas e políticas. Segundo este processo, instituições passadas são instrumentais em criar o ambiente econômico que dará origem às novas instituições. Com efeito, o modelo gera endogenamente seu próprio conjunto de possibilidades institucionais futuras (Setterfield, 1993, p. 766).

Ao tornar endógenos ao sistema todos os agentes e grupos sociais, Noyola desenvolve um modelo compatível com a dinâmica de complexidade, em que a sucessão de estados do sistema é dependente das contingências históricas (isto é, tem longa memória) e resultante da interação estratégica entre grupos sociais pelo controle das instituições. Trata-se de uma teoria de não-equilíbrio que considera irreversível não apenas o tempo histórico que enquadra sua análise, mas também os resultados das disputas entre grupos. Ou seja, uma vez que uma coalizão política assume o poder, o controle das instituições passa a incorporar seu conjunto de preferências.

De acordo com Danby (2001, p. 22), Noyola propõe "uma teoria política em que são as propriedades integradas do todo que importam, não as qualidades isoladas de suas partes". Este "holismo analítico" de Noyola faz do governo (e das finanças públicas) um "agente" (e uma variável) sensível à própria história do sistema econômico. O governo não é uma força exógena, apartada dos outros agentes e grupos envolvidos no jogo econômico e, por este motivo, não é politicamente neutra, investida senão das ferramentas e dos objetivos puramente técnicos de maximização do bem-estar coletivo, como retratado pelos modelos da ortodoxia keynesiana à época ${ }^{14}$.

É possível captar nesta abordagem uma aplicação avant-la-lettre do conceito de histerese institucional advogado por Setterfield (1993, p. 766), como vimos na segunda seção. Noyola descreve um processo de "procriação institucional", o qual resulta da propriedade de dependência de trajetória da evolução das instituições econômicas e políticas. Instituições passadas são instrumentais em criar o ambiente econômico que dará origem às novas instituições. Com efeito, o modelo gera endogenamente seu próprio conjunto de possibilidades institucionais futuras.

Noyola se afasta, portanto, da abordagem "reducionista" da Nova Economia Institucional, em que os agentes renegociam a cada instante o conjunto institucional mais eficiente (Langlois, 1986). Ao contrário, para o autor mexicano, a sensibilidade da mudança institucional à história do sistema (e às forças em disputa por seu controle, vale repetir) implica logicamente a possibilidade de persistirem indefinidamente arranjos institucionais socialmente ineficientes no sentido de Pareto, isto é, a ausência de arranjos alternativos que aprimorem o bem-estar de um indivíduo sem prejudicar o de outro. Para tanto, basta que os mesmos reforcem o poder econômico e político daqueles grupos no comando das instituições em determinado momento histórico (Rutherford, 1989; Bardhan, 1989).

(14) Danby salienta que, para Noyola: "Os Estados não são neutros nesta teoria. O governo não atua apenas como um árbitro de conflito de classe, mas já está intimamente envolvido neste último - não se pode fazer a separação tecnocrática entre governo e sociedade. É por isso que o quadro de Noyola incluiu políticas fiscais, monetárias e cambiais como mecanismos, como conexões, não como parâmetros exógenos ou ferramentas de políticas" (Danby 2005, p. 169-170. Tradução nossa). A despeito da caracterização otimista de Danby, acima, é controverso alegar que Noyola expôs claramente uma teoria do Estado, como se vê na discussão do livro de Carlos Bazdresch sobre o pensamento do autor mexicano (ver Noyola Vázquez, 1987, p. 165). Estudos mais detalhados podem esclarecer quanto da descrição de Danby pode ser efetivamente extraída dos escritos de Noyola e quanto é deduzido a partir do que ele não disse. 
Esta visão é particularmente ilustrativa do entendimento de Noyola a respeito da dinâmica do subdesenvolvimento (Bazdresch, 1983, p. 582-584). De forma resumida, Noyola entende que o subdesenvolvimento resulta da tentativa de expansão dos mercados nos países desenvolvidos, quando a produtividade alcançada por intensas inovações se viu restringida pela deficiência de demanda em seus mercados internos e pelo aumento no poder de barganha dos trabalhadores. As empresas estrangeiras passaram então a buscar trabalho e matérias primas mais baratas, com vistas a elevar a rentabilidade dos investimentos. No entanto, ao penetrarem os esquemas produtivos destes países, as empresas estrangeiras não promovem a mesma modernização econômica, tecnológica e institucional que o desenvolvimento do capitalismo imprimiu nos países centrais. Resultado de uma interação específica, não se forma nem uma "burguesia nacional" nem um "capitalismo autóctone". Não é do interesse das empresas estrangeiras o desenvolvimento local que levaria ao aumento do poder dos trabalhadores e consequentemente à elevação de custos produtivos. Formam-se alianças com as elites locais para bloquear o avanço de forças sociais que acompanham o desenvolvimento e que ameaçam a estrutura social vigente.

Com efeito, o atraso atravessa todas as dimensões das sociedades periféricas. O capitalismo não se torna a forma dominante de organizar a produção, os setores produtivos se modernizam de forma desigual e com viés primário-exportador, de forma que o atraso industrial torna estas sociedades altamente dependentes do ritmo de expansão dos mercados internacionais. Não demoram, portanto, a aparecer o desemprego estrutural e disfarçado (Robinson, 1936; Rosenstein-Rodan, 1943) nas aglomerações urbanas, os grandes desequilíbrios na distribuição da renda e a instabilidade política. Por isso, não se pode abstrair o funcionamento das economias nacionais de toda a organicidade que caracteriza a relação de dependência entre centro e periferia. A quase identificação entre capitalismo, dependência e subdesenvolvimento torna-se um elemento indispensável para a análise da evolução econômica da América Latina.

O subdesenvolvimento emerge, portanto, como uma propriedade das condições históricas de um sistema econômico em que a interação de suas frações segue regras hierárquicas de organização (termos de troca e elasticidades de demanda de importação diferenciais, conforme Prebisch, 1949). Além disso, a dinâmica interativa depende de aspectos "ambientais" e "genéticos", como a estrutura da economia regional e local (redes de comércio internacional, escala do mercado doméstico, composição setorial, estoque de capital e de tecnologia), a disponibilidade de recursos (humanos e naturais), o perfil de distribuição da renda e de acumulação de riqueza, bem como a organização política que disciplina o processo produtivo.

A perspectiva complexa sobre a obra de Noyola revela a premissa, adotada sobre base empírica, de que as economias são sistemas institucionais que aprendem com sua própria experiência histórica. A trajetória de "aprendizagem" é uma função de: (1) suas condições institucionais e estruturais iniciais e (2) relações de poder entre os grupos sociais que se revezam no direcionamento da manutenção, reforma e/ou revolução das primeiras. A interação do binômio poder-economia (2) com as condições iniciais (1) pode colocar a sociedade em um caminho de transformações mais ou menos profundas. Podem-se alterar as próprias relações orgânicas que estruturam os canais de causação lógica entre as partes, atenuando ou acentuando - e até mesmo revertendo - algumas relações de causa e efeito. 
O estudo comparativo que Noyola Vázquez (1956) faz das inflações chilena e mexicana dos anos 1950, proporciona uma ilustração bem didática de sua abordagem com elementos de complexidade. Primeiramente, a inflação é entendida como uma consequência da ausência de coesão política das frações da sociedade, Estado inclusive, as quais não logram atingir um consenso sobre o adequado perfil de distribuição da renda. A escalada dos preços resulta, portanto, da defesa da renda real por parte destes grupos. A incapacidade do Estado em disciplinar este conflito de forma decisiva está na raiz da persistência inflacionária. Com efeito, enquanto no caso mexicano, apesar de elevada, a inflação era menos aguda dado o arrocho salarial imposto pelo governo "à custa de alguma violência", no caso chileno, a ameaça à estabilidade do Estado (que se viu incapaz de impor sobre o salário real dos trabalhadores o fardo da estabilização) degenera em acelerada inflação e não pode ser revertida à situação anterior pelas vias institucionais disponíveis (Danby, 2005, p. 169).

Esta irreversibilidade decorre do fato de que, conforme a inflação demora a ceder, os grupos sociais desenvolvem mecanismos institucionais de coexistência com um problema que parece não ter uma solução clara nem politicamente viável (Heymann; Leijonhufvud 1995, cap. 2). As reações defensivas a este impasse social, que engolfa o próprio Estado, cristalizam-se em padrões de comportamento que emergem como novas normas sociais e que, uma vez colocados em ação, são resistentes a mudanças e, principalmente, às propostas de desmantelamento dirigido dos arranjos institucionais e administrativos que lhe dão suporte. Este é o caso exemplar da indexação de preços, salários, impostos, alugueis etc., como atesta Noyola para o caso chileno:

O caso chileno é um caso muito interessante por que demonstra como uma estrutura econômica pode criar mecanismos de defesa contra a inflação. Na economia chilena todos os grupos - e isto explica o limitado efeito distributivo da inflação chilena -, sabem se defender contra a inflação. Não há renda oriunda de rendas fixas; (...) os aluguéis das casas, as apólices de seguros, as pensões do seguro social, todas estão em maior ou menor medida atreladas ao custo de vida. Isto demonstra que muitas das ideias que se têm sobre os efeitos de uma inflação na estrutura e na distribuição da renda e na organização da economia não são tão importantes. No Chile os aluguéis são pagos aos proprietários das casas e se reajustam a cada seis meses, ou se reajustavam no ano passado a cada seis meses, de acordo com o aumento do custo de vida (Noyola Vázquez, 1987, p. 93. Tradução nossa).

A ideia de que uma inflação positiva não seria necessariamente nociva ao crescimento econômico era uma posição intelectual bastante disseminada à época em que Noyola escreveu, como mostrou Leeson (1997). O florescimento em várias partes do mundo de complexos sistemas de indexação resultou tanto da realidade observável de uma inflação positiva quanto de uma percepção abrangente quanto à sua adequação social, que incluía a profissão do economista e o arranjo de poder que legitimava a atuação do Estado (Page; Trollope, 1974; Fischer, 1981). Com efeito, se, por um lado, a indexação disciplinava e atenuava o conflito distributivo, por outro, ela não alterava o perfil distributivo inicial que deu origem ao impasse inflacionário, garantindo, portanto, a sua perpetuação. Não se deve, daí, deduzir que se trata necessariamente de uma anomalia, ou de um estado de desequilíbrio institucional e econômico em vias de desencadear uma convulsão social. ${ }^{15}$ Tais arranjos

(15) Bronfenbrenner e Holzman (1963) fazem uma abrangente revisão da literatura sobre inflação até final da década de 1950. Ao abordarem a teoria da inflação por conflito social, os autores salientam a contribuição de Henri Aujac, um economista francês que muito influenciou Noyola, como este próprio reconhece (Noyola Vázquez 1956). Ver também Bronfenbrenner e Holzman (1963, p. 623). 
podem persistir indefinidamente como uma sucessão de desequilíbrios, característica esta que Leijonhufvud (1997, p. 321) associou de forma mais geral a sistemas complexos, particularmente, às experiências de alta inflação.

Está além do escopo deste artigo uma análise mais detalhada da breve carreira de Noyola e as variadas aplicações de seu quadro analítico inovador como pesquisador e homem de ação envolvido com instituições de renome como o FMI e a CEPAL (Craven, 1994) e atuando diretamente no governo pós-revolução cubana (Noyola Vázquez, 1987). Nosso intuito nesta seção foi mostrar uma instância clara do pensamento do autor que se ajusta à abordagem da complexidade. É também possível que outras categorias analíticas desenvolvidas pelo autor sejam compatíveis com este tipo de análise. Todavia, a importância secundária das mesmas em sua obra nos impede de avançar sem sensível perda de rigor. Afortunadamente, seu colega e amigo Celso Furtado viveu uma vida longa e muito prolífica intelectualmente (sem mencionar em termos práticos). Sua obra nos oferece insumos mais abundantes para estabelecer a ponta analítica aqui pretendida.

\section{Furtado e a economia como um organismo complexo}

Nesta seção apresentam-se várias instâncias do pensamento de Furtado que guardam compatibilidade com a abordagem da complexidade. O problema do subdesenvolvimento, sob a ótica furtadiana, pode ser encarado como uma propriedade emergente - quiçá evolucionariamente estável - do sistema econômico internacional baseado em relações centro-periferia (ou dinâmica Norte-Sul). Suas conclusões a respeito do período desenvolvimentista brasileiro, recorrendo à interação analítica de fatores internos e externos - micro e macroeconômicos - entre economia e sociedade e entre teoria econômica e história econômica, apontam para a manutenção do lock in alcunhado de armadilha histórica do subdesenvolvimento (Furtado, 1992) mesmo diante da transformação na estrutura produtiva provocada pela industrialização no período desenvolvimentista.

Celso Furtado desempenhou papel crucial na composição do pensamento econômico brasileiro, para a compreensão da formação econômica e social do Brasil e para se pensar criticamente a respeito de políticas de desenvolvimento econômico. E talvez, justamente por conta de sua riqueza, complexidade e abrangência, a obra de Celso Furtado é passível de diversas críticas e ponderações, as quais, historicamente, desencadearam importantes desenvolvimentos teóricos e metodológicos posteriores, o que, do ponto de vista do evolver científico e do cumprimento da função social da ciência, é extremamente desejável ${ }^{16}$.Também nesse sentido, Furtado (1954b) já reconhecia a limitação do ferramental então disponível da Economia em tratar da totalidade de aspectos que abrangem o desenvolvimento. Em suas palavras:

A teoria do desenvolvimento econômico não cabe, nos seus termos gerais, dentro das categorias da análise econômica [...] A análise econômica não nos pode dizer por que uma sociedade se

(16) No livro “A Pré-Revolução Brasileira”, o autor afirma que "Para evitar esse dilema entre atitudes antissociais, conscientes ou inconscientes, de parte dos economistas com responsabilidade na política econômica, é mister que alcancemos um mais alto grau de independência no plano das formulações teóricas. É necessário que realizemos um esforço continuado no sentido de enriquecer e vivificar as teorias econômicas que nos chegam e mesmo no reformulá-las, toda vez que as hipóteses convencionais não possuam o poder explicativo necessário para abarcar a realidade sobre a qual devemos atuar" (1962, p. 70-71). 
desenvolve e a que agentes sociais se deve esse processo. Não obstante, a análise econômica pode precisar o mecanismo do desenvolvimento econômico (Furtado, 1954b, p. 321).

A obra de Furtado é sabidamente extensa e abrangente - mais de trinta livros, publicados entre a década de 1950 e de 2000 . Pouco antes de Noyola elaborar sua visão do processo inflacionário, Furtado (1954a, p. 173-187) lança as bases do que três décadas mais tarde viria a se chamar a teoria da inflação inercial (Carvalho 2019, p. 50-51). Ao analisar os dois lados do processo inflacionário, Furtado analisa o "equilíbrio dinâmico" da escala de preços, entendido como um processo de "luta pela redistribuição de renda". Em meio a uma inflação persistente, os grupos desenvolvem uma noção da posição que ocupam no perfil distributivo da economia em cada momento e se põem a defender suas rendas da erosão do poder de compra. Isso pode ser feito institucionalmente por meio de indexação de contratos ou de preços - ou economicamente por meio de demandas periódicas por reajustes de preços e salários. A marca evolucionária, na mesma linha de Noyola, aparece nesta interação complexa entre uma racionalidade instrumental e de alcance limitado, um ambiente inflacionário persistente e uma institucionalidade maleável e responsiva aos eventos econômicos. Como resultado, emerge uma propriedade típica de economias cronicamente inflacionárias, a saber: uma estabilização bem-sucedida se torna uma tarefa problemática devido a uma estrutura escalonada de reajustes de contratos, de preços e de salários.

É nas discussões teóricas mais gerais do autor sobre o desenvolvimento e as especificidades do subdesenvolvimento que encontramos ainda mais explicitamente os elementos da abordagem da complexidade. Em prefácio à edição francesa de seu livro quiçá mais marcadamente teórico sobre o desenvolvimento, Furtado (1967) define a teoria do desenvolvimento como a tentativa de explicação das transformações dos conjuntos econômicos complexos. E, no mesmo tom da citação anterior, o autor explicita algumas das limitações da teoria econômica naquele momento:

Ao estabelecer a significação do não-econômico nas cadeias de decisões que levam à transformação dos conjuntos econômicos complexos, a teoria do desenvolvimento encarrega-se de pôr a descoberto suas próprias limitações como instrumento de previsão (Furtado, 1967, p. xiii).

Essa discussão é retomada no decorrer do mesmo livro, quando o autor indica a necessidade de combinarem as perspectivas macro e microeconômica por conta da complexidade envolvida no desenvolvimento de teorias em Economia, conforme citação já apresentada na primeira seção desse artigo.

Segundo Furtado, o problema metodológico que estaria posto ao economista seria o de definir o nível de generalidade de seus modelos abstratos sem que isso invalidasse a sua eficácia explicativa, quando confrontados com a realidade histórica. Tal problema metodológico assumiria destacada importância na teoria do desenvolvimento, pois: (1) não haveria como eliminar o fator tempo ou eliminar a irreversibilidade dos processos históricos; e (2) não seria possível ignorar as diferenças estruturais entre as economias com graus diversos de desenvolvimento. Dessa discussão, por sua vez, decorre o caráter cumulativo e dependente da trajetória dos processos transformadores pelos quais passam as nações. Quanto ao fator (2), o qual, em boa medida, deriva de (1), enfatiza a importância da consideração, por parte da teoria do desenvolvimento, da heterogeneidade das nações, especialmente quando se comparam nações centrais e nações periféricas (Cardoso, 2018). Então, 
sobre a questão metodológica, Furtado conclui que "A complexidade da ciência econômica - seu caráter abstrato e teórico - aparece, assim, com toda a plenitude na teoria do desenvolvimento econômico" (Furtado, 1967, p. 4).

Nesse mesmo sentido, Furtado (1961) salientara que as distintas dotações de fatores, as diferentes características institucionais e os diversos graus de desenvolvimento faziam de cada economia nacional um fenômeno particular de desenvolvimento. Por outro lado, embora o desenvolvimento econômico fosse um fenômeno com nítida dimensão histórica, uma vez que o processo de desenvolvimento de cada economia levava ao enfrentamento de problemas específicos, isso não significaria que o trabalho do economista deveria se limitar a uma simples descrição de casos históricos de desenvolvimento, requerendo, para tal, um instrumental analítico adequado. E a inspiração principal para tal instrumental analítico, segundo Furtado (1967), viria de três grandes pensadores: Keynes, Schumpeter e Marx.

Em linhas gerais, uma particularidade da abordagem Furtadiana, presente em toda a sua obra, é seu aspecto interdisciplinar. Implícita a essa escolha teórica está, como já indicado acima, a não consideração da suposta suficiência dos fatores econômicos para a compreensão do processo de desenvolvimento. No entanto, mais do que não considerar a suficiência dos fatores econômicos, Furtado não restringe sua análise a fatores estritamente econômicos. Como bem destaca Cepêda (2008), a interpretação de economia brasileira empreendida por Furtado conecta questões sociais e econômicas de maneira inédita no pensamento brasileiro.

Relacionada à consideração de aspectos sociológicos, estaria a conexão subjacente ao trabalho de Furtado, entre teoria e história ${ }^{17}$, o que faz de sua obra uma fonte informativa importante tanto do ponto de vista estritamente teórico, quanto do ponto de vista estritamente histórico. Exatamente por ter sido construído firmemente sobre esses dois pilares, o método de Furtado seria bastante adequado à discussão dos temas concernentes ao desenvolvimento e ao subdesenvolvimento econômicos; e, também pela sua organicidade, levando em consideração fatores de diversas naturezas.

Coutinho (2008) destaca que a abordagem teórica de Furtado contempla um duplo caráter, o abstrato e o real, que não pode ser negligenciado pela análise econômica, constituindo o real um limite importante à construção abstrata. Segundo o autor, "Com efeito, este foi o compromisso permanente de Furtado: a aplicação de princípios gerais a realidades econômicas dotadas de historicidade" (Coutinho, 2008, p. 142).

De acordo com Furtado, o conceito de desenvolvimento compreende a ideia de crescimento superando-a, uma vez que, para que seja configurado, deve satisfazer às múltiplas necessidades do conjunto econômico nacional, estando ainda sob a ação contínua de uma grande multiplicidade de fatores sociais e institucionais. Diz o autor: "o crescimento de um conjunto complexo sem desenvolvimento seria aquele do qual estivesse ausente toda modificação na estrutura" (Furtado, 1967, p. 92). Essa não correspondência direta entre crescimento e desenvolvimento seria ainda mais evidente no caso das economias periféricas ou dependentes. Novamente nas palavras do autor:

(17) Sobre a relação entre teoria e história na obra de Furtado, diz Oliveira que "O novo em Celso Furtado, assim como nos clássicos demiúrgicos da década de 1930, é a construção de uma complexa relação entre teoria e história” (Oliveira, 2003, p. 84). 
Pode-se conceber a hipótese de crescimento sem desenvolvimento no caso de uma economia dependente, na qual todos os benefícios do progresso técnico do setor exportador fossem retidos no exterior. O desenvolvimento, neste caso, se manifestaria no conjunto maior que inclui tanto a economia dominada como a dominante (Furtado, 1967, p. 92, n. 2).

Retomando a afirmação do início da presente seção, conforme Furtado, o subdesenvolvimento emerge como resultado das relações centro-periferia. Porém, não se trata apenas de responsabilizar o centro pela manutenção da condição de subdesenvolvimento na periferia. Há que se buscar, internamente à periferia, fatores que expliquem a manutenção e recrudescimento da relação de dependência com os países centrais e que, em conjunto com essa relação de dominância e poder político e econômico, fazem emergir a armadilha do subdesenvolvimento. No conjunto de fatores internos residem justamente os fatores estruturais e institucionais, que envolvem toda a configuração de modelo produtivo e distributivo da economia, assim como fatores políticos - leia-se, relações de poder entre grupos de interesse e classes sociais - e também culturais - que, em boa medida, podem refletir igualmente relações de poder ${ }^{18}$.

Nesse sentido, segundo Furtado (1975), o conceito de economia nacional é fundamental à teoria do desenvolvimento, pois permite integrar duas esferas de decisão, quais sejam, as decisões econômicas e as decisões políticas. O autor situa o estudo das economias nacionais no escopo da teoria dos sistemas abertos ${ }^{19}$, pois seria difícil saber “[...] se esta ou aquela decisão decorre da pressão de forças internas ou externas, ou de forças internas autônomas ou funcionalmente integradas com interesses externos" (Furtado, 1975, p. 35). Essa observação ganha especial importância no caso das economias subdesenvolvidas, por conta da importância dinâmica das relações externas. Nas palavras do autor:

As relações externas decorrem, seja da participação em mercados internacionais particulares, seja do controle externo de decisões relacionadas com a produção e o investimento. Em um e outro casos o conteúdo político das decisões econômicas pode ser maior ou menor, em função da importância relativa e da natureza das atividades controladas do exterior. E quanto maior esse conteúdo político, mais difícil será encontrar coerência interna no sistema econômico se se pretende analisá-lo como um sistema fechado (Furtado, 1975, p. 35).

Furtado destaca que as nações periféricas não possuiriam centros próprios de decisão capazes de efetivamente coordenar as suas atividades internas. ${ }^{20}$ Segundo o autor, nesses casos, "Os

(18) Dentro da abordagem furtadiana, destaque-se o papel do padrão consumo voltado aos bens de luxo ditado desde os países do centro, emulado pelas classes mais ricas da periferia e desejado pelas classes menos abastadas. Em suas palavras: "[...] na economia dependente existirá, sob a forma de um "enclave" social, um grupo culturalmente integrado nos subsistemas dominantes. O dualismo tem, portanto, desde o início uma dimensão cultural (...) Para o economista que observa uma economia subdesenvolvida como um sistema fechado, esse fenômeno se apresenta como um "desequilíbrio ao nível dos fatores", decorrente da "inadequação" da tecnologia. Escapa-lhe que o referido fenômeno é, fundamentalmente, uma decorrência de formas de comportamento ligadas ao quadro estrutural da dependência" (Furtado, 1967, p. 249-250). Ou ainda: "A forma particular de difusão dos frutos de um progresso tecnológico socialmente orientado cria para a minoria que se apropria do excedente uma situação de dominação cultural, a partir da qual ela legitima ideologicamente o sistema político" (Furtado, 1975, p. 44).

(19) Em termos termodinâmicos, sistema aberto seria aquele no qual energia e matéria fluem dele e para ele, podendo esse sistema utilizar esse fluxo de energia e matéria para fazer frente à entropia e, assim, criar ordem, estrutura e padrões por um período de tempo (Beinhocker, 2006, p. 70). Esse conceito aplicado às nações implica que suas ações influenciam a dinâmica geral do sistema econômico e político mundial e que nenhuma nação está isenta de sofrer influências externas.

(20) A essa mesma conclusão chegam os teóricos da dependência, que concedem grande peso ao fator político como explicação para a manutenção da situação de dependência e, por isso, dos limites do desenvolvimento da periferia. 
ajustamentos oferta-demanda dependem do comércio exterior. Em todo caso, trata-se de estruturas rígidas com escassa capacidade de adaptação" (Furtado, 1975, p. 56). Assim, conclui o autor que a deterioração dos termos de intercâmbio dos exportadores de bens menos complexos, tal como destacado pela tese Singer-Prebisch, teria a raiz de seu problema residindo na rigidez estrutural e na incapacidade dos centros internos de decisão em introduzir as modificações necessárias nessas estruturas, compondo essa a questão crucial do fenômeno da dependência externa. E, aqui, mais uma vez depara-se com a limitação de transformação na direção do desenvolvimento implicada pelas instituições, resultado da ação de grupos específicos, de tendência conservadora, com maior poder político e econômico.

Relacionado à questão de dependência externa, Furtado (1961) destaca que, ao crescerem pela simples assimilação de técnicas já existentes ${ }^{21}$, os países subdesenvolvidos incorreriam no risco, quase certo, de provocar subemprego estrutural de fatores. Para o autor, "Nesse desajustamento básico entre oferta virtual de fatores e orientação da tecnologia reside, possivelmente, o maior problema que enfrentam atualmente os países subdesenvolvidos" (Furtado, 1961, p. 86). Parte da explicação para a falta de correspondência entre a disponibilidade de recursos e as combinações deles requeridas pela tecnologia que estava sendo absorvida do exterior residiria no caráter exógeno das transformações que se observavam nas economias subdesenvolvidas por meio, especialmente, da inserção de empresas estrangeiras, que ainda resguardavam estruturas pré-capitalistas e seriam ainda tecnologicamente defasadas.

No que se refere às suas conclusões sobre a experiência brasileira no período desenvolvimentista, vale ressaltar novamente a importância concedida por Furtado às reformas estruturais - ou reformas de base, conforme denominara na elaboração do Plano Trienal - como condições necessárias para que os efeitos transformadores provenientes das modificações na estrutura produtiva brasileira pudessem ao menos ter chances de se traduzir em melhores condições de vida da maioria da população brasileira, atenuando os grandes níveis de disparidade regional e de desigualdade distributiva. E, provavelmente, na ausência dessas transformações estruturais, residiria parte das explicações para a estratégia de desenvolvimento adotada pelo Brasil no período desenvolvimentista não ter levado à emergência do desenvolvimento econômico, e sim à perpetuação da sua condição de subdesenvolvimento.

Transformar a base produtiva na direção de incrementar sua concentração em atividades de mais alto valor agregado - e, por isso, com maior potencial de efeitos de encadeamento à la Hirschman - era, portanto, uma condição necessária, porém longe de ser suficiente para que o Brasil se libertasse da armadilha do subdesenvolvimento. Observação que, se por um lado, ajudaria a corroborar o fato de o desenvolvimento necessariamente extrapolar o escopo da Economia, por outro lado, colocaria em destaque que, mesmo aquelas reformas estruturais que teriam motivação e racionalidade econômicas implícitas, acabaram não sendo satisfatoriamente promovidas.

A ausência de mudanças estruturais e institucionais relacionadas à estrutura agrária, à estrutura tributária, à estrutura fiscal, à educação e à tecnologia, teria contribuído para a perpetuação

(21) Como bem destaca Furtado (1961) haveria uma interdependência “[...] entre a evolução da tecnologia nos países industrializados e as condições históricas do seu desenvolvimento econômico. Essa tecnologia, na forma em que se apresenta hoje, incorporada aos equipamentos industriais, resulta, portanto, de um lento processo de decantação" (Furtado, 1961, p. 159). 
e acentuação da diversidade de desequilíbrios perniciosos à sustentação do processo de desenvolvimento econômico enfrentados pelo Brasil e pela periferia em geral. Esse é o cerne do argumento cepalino-estruturalista, que o diferencia da perspectiva desenvolvimentista anglo-saxã (Cardoso, 2018).

Há que se notar, no entanto, que também as reformas estruturais e/ou mudanças institucionais não seriam uma condição suficiente para garantir o resultado de desenvolvimento. Por outro lado, na ausência delas, se perpetuariam as fontes de desequilíbrios, disparidades, problemas e desordem que faziam com que os efeitos propulsores - ou, efeitos multiplicadores da renda e do emprego desencadeados pelas transformações da estrutura produtiva se dispersem. Sem a resolução dessas questões estruturais e institucionais, tornava-se ainda mais difícil superar a armadilha do subdesenvolvimento.

A análise de Furtado está sempre atenta à interação dinâmica de diversos fatores, econômicos e não econômicos, internos e externos, micro e macroeconômicos, traduzida em círculos viciosos e causações circulares multifatoriais e multidirecionais, que envolvem aspectos socioeconômicos, políticos e culturais.

No cerne desses nós que implicam tais causações circulares que resultam na armadilha do subdesenvolvimento, estão localizadas as instituições, tal como refletidas a partir dos interesses dos grupos que controlam as esferas política e econômica. Daí derivam os dois resultados vistos acima, a saber: o aprisionamento na condição de subdesenvolvimento (mesmo diante de transformações significativas na estrutura produtiva) e o impasse inflacionário (em sua versão dinâmica, como vimos no início desta seção). No tocante a este último aspecto, Furtado salienta que, uma vez que o processo inflacionário autonomiza plenamente os mecanismos propagação de choques, os agentes apenas se revezam nas tentativas de manter o seu poder de compra, neutralizando o objetivo final da inflação que é redistribuir renda. A relação entre crescimento e inflação perde a demarcação paramétrica típica da abordagem monetarista. Com efeito, uma política ortodoxa de contenção de demanda pode acirrar o conflito distributivo, penalizando aqueles menos equipados para defender seu emprego e da erosão de seu poder de compra. E aqui novamente retoma-se o conceito de histerese institucional de Setterfield: a mudança institucional pode resultar em ineficiências especialmente porque tende a refletir os interesses de grupos específicos que não necessariamente buscam o bem-estar social geral.

\section{Complexidade e desenvolvimento econômico: à guisa de conclusão}

Marshall fez uma controversa proposição metodológica em seu clássico Princípios de Economia: a biologia, e não a física, deveria ser a "meca" da Economia. Esta famosa assertiva de um expoente da abordagem do equilíbrio parcial mostra que, muito antes do tempo dos autores assinalados no presente artigo, já não era nova a percepção de que o problema econômico seria mais ricamente compreendido se o individualismo metodológico desse lugar a uma perspectiva interativa e evolucionária; afinal, uma catedral não é apenas um amontoado de tijolos, assim como a sociedade não é a mera soma dos indivíduos. Mas afinal, como a abordagem da complexidade pode enriquecer o nosso entendimento sobre o desenvolvimento econômico? E por que lançar mão de dois pensadores estruturalistas que escreveram em meados do século passado? 
A abordagem da complexidade capta o fenômeno econômico de forma mais abrangente e, por isso, ilumina um conjunto enorme de casos que, na abordagem convencional, seriam vistos como "anomalias" ou "desvios" de uma trajetória de equilíbrio baseada na busca de unicidade e estabilidade do sistema econômico. Ao livrar a Economia das amarras do conceito de equilíbrio, extraído da física clássica, a abordagem da complexidade incorpora a não-linearidade e a multiplicidade de equilíbrios possíveis, sujeitos ou não à estabilidade, sendo esta entendida como parte de um processo evolucionário em que todos os agentes são considerados "variáveis endógenas". Abdica-se, portanto, da noção metodologicamente heroica e historicamente falaciosa, defendida pela teoria neoclássica do equilíbrio geral, de um Estado ou mercado ex-machina (ou "exógeno" ao sistema) que, por ser mais bem informado do que os grupos e indivíduos, carrega a economia a uma trajetória de sela estável. Ao tratar a economia como um organismo complexo, um dado equilíbrio é visto como uma "opção" política gravada nos arranjos institucionais em vigor, os quais se veem como objetos mesmos de conflito entre os grupos que formam a sociedade, considerando a burocracia estatal inclusive.

Desde esta perspectiva complexa, portanto, o subdesenvolvimento deixa de ser um estado transitório na espontânea marcha da convergência econômica entre todos os países, constituindo-se num problema ou fenômeno emergente resultante da interação centro-periferia. Nenhum país, grupo social ou indivíduo é uma ilha. A interação é o nome do jogo, o qual conta com jogadores heterogêneos dotados de variados graus de destreza, de experiência política, de coesão intragrupo e intergrupos e, por conseguinte, dotados desigualmente com recursos de poder econômico e político. Neste quadro analítico, a espontaneidade deixa de ser uma propriedade normativa de um equilíbrio estático (e único) para assumir contornos variados, podendo levar tanto a situações socialmente desejáveis - como o desenvolvimento - quanto a armadilhas com fortes amarras autorreforçantes. Assim, fenômenos como o subdesenvolvimento, o atraso tecnológico e a inflação galopante e persistente emergem, não como "erros", mas como propriedades emergentes da interação evolucionária dentro de sistemas orgânicos. Não surpreende, portanto, a compatibilidade metodológica entre a abordagem da complexidade e aquelas que enfatizam aspectos institucionais e estruturais do subdesenvolvimento, do desenvolvimento desigual e da persistência de heterogeneidade econômica, institucional e de comportamento.

A inexistência de uma "caixa de ferramentas" à altura de oferecer uma alternativa competitiva ao rigor matemático (e mortis) da teoria neoclássica não impediu que muitos autores vislumbrassem a economia como sistemas orgânicos complexos. Ademais, a data em que um método é rotulado não coincide com o início de sua existência material e prática, como se percebe na gama de exemplos históricos deste ponto analisados em Colander (2000). Por isso, buscou-se salientar que a contribuição conjunta de Noyola e Furtado carrega fortes traços de complexidade, ainda que desenvolvidos apenas discursivamente.

Noyola buscou adotar o maior grau de desagregação possível em suas análises centradas sobre o desequilíbrio social e dinâmicas de ajustamento, de sorte a singularizar os processos distributivos que caracterizavam diferentes experiências históricas de (sub)desenvolvimento econômico. O autor entendia a economia como um complexo de grupos sociais com preferências e comportamentos motivados por fatores que transcendiam em muito o campo econômico e se manifestavam, via recursos de poder, na configuração institucional do Estado, na propriedade concentrada da terra, na posição vantajosa dos banqueiros e rentistas no controle monetário via 
crédito, e na primazia dos empresários na determinação de preços logo após a celebração de acordos salariais com os trabalhadores.

Muito alinhado ao pensamento francês de François Perroux e Henri Aujac, a inflação não seria, para Noyola, mero resultado de excesso monetário do Estado, mas de uma dinâmica interativa dentro de uma complexa rede de "balanços monetários" em que cada agente e/ou grupo tenta repassar o fardo do ajuste do sistema para o próximo grupo. Controlar a inflação via demanda agregada seria, portanto, uma "opção" dos grupos econômicos mais poderosos - não um imperativo teórico e prático. Noyola tentou mostrar que tal fixação com o controle da inflação poderia reforçar o subdesenvolvimento ao sufocar o crescimento econômico. Ele defendeu, no entanto, que um resultado "perverso" como este poderia ser legitimado socialmente. Uma vez consideradas a "estrutura econômica", a relativa solidez das "instituições" monetárias e fiscais, e a disputa política pelo comando destas últimas, o subdesenvolvimento emergiria como uma "armadilha estrutural e institucional" (lock-in) que beneficiaria desigualmente os grupos econômicos mais bem posicionados socialmente. O planejamento econômico via Estado seria, portanto, uma forma de romper esta coalizão de grupos e formar uma correlação de forças alternativa, cujo objetivo fosse a mudança estrutural e institucional rumo ao desenvolvimento industrial. Este processo aliviaria as restrições de balanço de pagamentos e de produção de alimentos que ciclicamente recolocavam o problema da inflação, gerando reações dos grupos sociais contra a política de desenvolvimento.

Foi com Furtado, porém, que a visão cepalina ganhou sofisticação analítica e abrangência histórica. $\mathrm{O}$ trade off entre crescimento e inflação também é abordado pelo autor, na mesma linha de Noyola: a busca pela estabilidade sem considerar a natureza dos problemas estruturais, que enfrentam especialmente os países subdesenvolvidos, pode ser totalmente perniciosa para o crescimento (Furtado, 1954, p. 187) e, consequentemente, para o desenvolvimento, mesmo que estritamente econômico. Sem embargo, para além da análise dos embates entre grupos de poder internos que implicam resultados que ou dificultam o crescimento ou levam a escolhas de políticas econômicas como a de estabilização via redução da demanda agregada - que impedem a retomada do crescimento, Furtado identifica o subdesenvolvimento como um resultado emergente das relações Norte-Sul, com predominância política, econômica e cultural do centro sobre a periferia. Essas relações, por sua vez, se reproduzem internamente, dessa vez entre as classes dotadas de mais poder político e econômico e as classes mais populares, gerando o que Setterfield denomina de histerese institucional e resultando que Furtado define como armadilha histórica do subdesenvolvimento. A conclusão de estruturalistas como Celso Furtado é implacável: sem reformas estruturais e institucionais profundas que alterem principalmente as condições de distribuição de renda e riqueza - e, portanto, que modifiquem a secular estrutura de poder - com vistas à diminuição da concentração, não há crescimento que se sustente, mesmo que impulsionado pela industrialização. Ou seja, o desenvolvimento não é consequência natural do crescimento econômico.

$\mathrm{Na}$ desnaturalização do resultado de desenvolvimento reside a contribuição da Abordagem da Complexidade à Economia do Desenvolvimento. Como já dito, não há trajetória nem única, nem garantida rumo àquele resultado. Não há nada que garanta a colocação de uma nação numa trajetória virtuosa de desenvolvimento, nem um suposto conjunto de instituições infalível e universal para tal intento, como sugeriria uma perspectiva excessivamente generalizante do processo de desenvolvimento, tal como de Rostow (1974) e North (1990). Há uma série de elementos que 
concorrem para que as trajetórias resultem ou não em configurações desejáveis econômica e socialmente. E, nesse quadro, as características estruturais e institucionais adquirem caráter crucial, uma vez que condicionam, mas também resultam da interação entre os diversos grupos, internos e externos.

Assim, o subdesenvolvimento não se trata de uma simples etapa rostowiana pela qual todas as nações passarão ou da não escolha de instituições universalmente eficientes, como argumentariam os northianos. O subdesenvolvimento, a partir de uma perspectiva complexa, tal como nos brindam Noyola e Furtado, resulta da manutenção de instituições ineficientes para a geração de desenvolvimento no contexto de nações com problemas estruturais particulares e esse resultado emerge a partir da ação de grupos de poder que tendem a buscar justamente a manutenção de suas condições iniciais de privilégios.

\section{Referências bibliográficas}

APRIGIO, Pedro Luiz; CARVALHO, André Roncaglia. Estabilidade monetária e CEPAL: a heterogeneidade do pensamento estruturalista latino-americano. Revista de Economia Política, v. 38, n. 1, p. 28-47, 2018. https://dx.doi.org/10.1590/0101-31572018v38n01a02.

ARTHUR, William Brian. Self reinforcing mechanisms in economics. In: ANDERSON, P. W.; ARROW, K.; PINES, D. (Ed.). The economy as an evolving complex system. Reading, Mass.: Addison- Wesley, 1988.

ARTHUR, William Brian. Complexity and the economy. New York: Oxford University Press, 2015. ARTHUR, William Brian; DURLAUF, S. N.; LANE, D. A. Introduction. In: ARTHUR, W. B.; DURLAUF, S. N.; LANE, D.A. (Ed.). The economy as an evolving complex system II. Reading: Addison-Wesley, 1997.

AUJAC, Henri. Inflation as the monetary consequence of the behaviour of social groups: a working hypothesis. International Economic Papers, n. 4 (originally published in French in Economie Appliquée, April/June 1950).

BADCOCK, Abbie. Can complexity save development theory? In: BOGG, Jan; GEYER, Robert (Ed.). Complexity, science and society, New York: Radcliffe Publishing, 2007.

BARDHAN, P. The new institutional economics and development theory: a brief critical assessment. World Development, n. 17, p. 1389-1395, Sept. 1989.

BAZDRESCH, P. C. El pensamiento de Juan F. Noyola. El Trimestre Económico, v. 50, n. 2 (198), p. 567-593, 1983. Disponível em: http://www.jstor.org/stable/23395693. Acesso em: 10 abr. 2017.

BEINHOCKER, Eric. The origin of wealth - Evolution, complexity, and the radical remaking of economics. Harvard Business School Press, 2006.

BRONFENBRENNER, Martin; HOLZMAN, Franklyn. Survey of inflation theories. The American Economic Review, v. 53, n. 4, p. 593-596, Sept. 1963. 
CARDOSO, Fernanda Graziella. A armadilha do subdesenvolvimento: uma discussão do período desenvolvimentista brasileiro sob a ótica da abordagem da complexidade. Tese (Doutorado)-FEAUSP, São Paulo, 2012.

CARDOSO, Fernanda Graziella. Nove clássicos do desenvolvimento econômico. Jundiaí: Paco Editorial, 2018.

CARVALHO, André Roncaglia. The conceptual evolution of inflation inertia in Brazil. Dissertation (PhD)-Faculdade de Economia, Administração e Contabilidade, Universidade de São Paulo, 2015.

CARVALHO, André Roncaglia. A second-generation structuralist transformation problem: the rise of the inertial inflation hypothesis. Journal of the History of Economic Thought, v. 41, n. 1, p. 47$75,2019$.

CEPÊDA, Vera Alves. Celso Furtado e a interpretação do subdesenvolvimento. In: LIMA, Marcos Costa; DAVID, Maurício Dias (Org.). A atualidade do pensamento econômico de Celso Furtado. São Paulo: Verbena Editora, 2008.

CHANG, Ha-Joon. Kicking away the ladder: development strategy in historical perspective. Anthem Press, 2002.

COLANDER, David. Complexity and the history of economic thought: perspectives on the history of economic thought. Selected papers from the History of Economics Society Conference. New York: Routledge, 2000.

COUTINHO, Maurício. A teoria econômica de Celso Furtado: Formação Econômica do Brasil. In: LIMA, Marcos Costa; DAVID, Maurício Dias (Org.). A atualidade do pensamento econômico de Celso Furtado. São Paulo: Verbena Editora, 2008.

CRAVEN, C. A transformation problem: monetarism to structuralism in the economic commission for Latin America. History of Political Economy, v. 26, n. 1, p. 1-19, 1994.

DANBY, C. Noyola's institutional approach to inflation. Journal of the History of Economic Thought, 27, p. 161-178, 2005.

DOW, Sheila. Framing financial markets: a methodological account. Brazilian Keynesian Review, v. 2, n. 2, p.160-173, $2^{\text {nd }}$ Semester 2016.

FISCHER, Stanley. Indexing and inflation. NBER, 1981. 35p. (Working Paper Series, n. 610).

FOLEY, Duncan. Unholy Trinity - Labor, capital, and land in the new economy, London: Routledge, 2003.

FURTADO, Celso. A economia brasileira. Rio de Janeiro: A Noite, 1954a.

FURTADO, Celso (1954b). Formação de capital e desenvolvimento econômico. In: AGARWALA, A.; SINGH, S. P. (Ed.). A economia do subdesenvolvimento. Rio de Janeiro: Cia Editora Forense, 1969.

FURTADO, Celso (1959). Formação econômica do Brasil, São Paulo: Companhia Editora Nacional, 2001. 
André Roncaglia de Carvalho, Fernanda Graziella Cardoso

FURTADO, Celso (1961). Desenvolvimento e subdesenvolvimento, Rio de Janeiro: Editora Contraponto, 2009.

FURTADO, Celso. A pré-revolução brasileira. Rio de Janeiro: Editora Fundo de Cultura, 1962.

FURTADO, Celso (1967). Teoria e política do desenvolvimento econômico. São Paulo: Companhia Editora Nacional, 1977.

FURTADO, Celso. (1975). Economia do desenvolvimento - Curso ministrado na PUC-SP em 1975. Arquivos Celso Furtado 2. Rio de Janeiro: Editora Contraponto; Centro Internacional Celso Furtado de Políticas para o Desenvolvimento, 2008.

FURTADO, Celso. Brasil - a construção interrompida. São Paulo: Paz e Terra, 1992.

FURTADO, Celso. Para onde caminhamos? Jornal do Brasil, 10 nov. 2004.

GEYER, Robert; RIHANI, Samir. Complexity and public policy - a new approach to 21 st Century politics, policy and society. London / New York: Routledge, 2010.

GOODWIN, R. M. The nonlinear accelerator and the persistence of business cycles. Econometrica, 19, p. 1-17, 1951.

HAUSMANN, Ricardo; HIDALGO, César A.; BUSTOS, Sebastián; CHUNG, Michele Coscia Sarah; JIMENEZ, Juan; SIMOES, Alexander; YILDIRIM, Muhammed A. The atlas of economic complexity - mapping paths to prosperity. Center for International Development at Harvard University, Harvard Kennedy School, Macro Connections MediaLab, MIT, 2015.

HEYMANN, Daniel; LEIJONHUFVUD, Axel. High inflation. Oxford: Oxford University Press, 1995.

HOLT, Richard P. F.; ROSSER, J. Barkley, Jr.; COLANDER, David. The complexity era in economics. Review of Political Economy, v. 23, n. 3, p. 357-369, 2011.

HORGAN, J. The end of science: facing the limits of knowledge in the twilight of the scientific age. New York: Basic Books, 2015.

KALDOR, Nicholas. A classificatory note on the determinateness of equilibrium. Review of Economic Studies, 1, p. 122-136, Oct. 1934.

KALECKI, Michal; SACHS, Ignacy (1966). Forms of foreign aid: an economic analysis. In: ESSAYS on developing economics. The Harvester Press Limited, 1976.

LANGLOIS, R. N. The new institutional economics: an introductory essay. In: LANGLOIS, R. N. (Ed.). Economics as a process. Cambridge: Cambridge University Press, 1986.

LEESON, Robert. The eclipse of the goal of zero inflation. History of Political Economy, v. 29, n. 3, p. 445-496, 1997.

LEIJONHUFVUD, Axel. Macroeconomics and complexity: inflation theory. In: ARTHUR; Durlauf; LANE (Ed.). The economy as an evolving complex system II. SFI Studies in the Sciences of Complexity, v. XXVII. Addison-Wesley, 1997. p. 321-335.

LEVINS, R.; LEWONTIN, R. . The dialectical biologist. Harvard University Press, 1985. 
MYRDAL, Gunnar (1957). Teoria econômica e regiões subdesenvolvidas. 2. ed. Rio de Janeiro: Editora Saga, 1968.

NORTH, Douglass. Institutions, institutional change and economic performance. Cambridge University Press, 1990.

NOYOLA VÁZQUEZ, Juan F. El desarrollo económico y la inflación en México y otros países latinoamericanos. Investigación Económica. v. XVI, n. 4, 1956.

NOYOLA VÁZQUEZ, Juan F. Desequilibrio externo y la inflación. Materiales Investigación Económica, 1987.

OLIVEIRA, Francisco de. Formação econômica do Brasil: gênese, importância e influências teóricas. In: OLIVEIRA, Francisco de (Org.). A navegação venturosa-Ensaios sobre Celso Furtado. São Paulo: Editora Boitempo, 2003.

PAGE, S. A. B.; TROLLOPE, Sandra. An international survey of indexing and its effects. National Institute Economic Review, n. 70, Nov. 1974.

PRADO, Eleutério Fernando da Silva. Microeconomia reducionista e microeconomia sistêmica. Revista Nova Economia, v. 16, n. 2, p. 302-322, maio/ago. 2006.

PREBISCH, Raúl (1949). O desenvolvimento econômico latino-americano e alguns de seus principais problemas. In: BIELSCHOWSKY, Ricardo (Org.). Cinquenta anos de pensamento da CEPAL. Rio de Janeiro: Record, 2000. v. 1.

RIHANI, Samir; GEYER, Robert. Complexity: an appropriate framework for development? Progress in Development Studies, v. 1, n. 3, p. 237-245, 2001.

ROBINSON, Joan. Disguised unemployment. The Economic Journal, v. 46, n. 182, p. 225-237, Jun. 1936.

ROSENSTEIN-RODAN, P. Problems of industrialisation of Eastern and South-Eastern Europe. The Economic Journal, v. 53, n. 210/211, p. 202-211, 1943. DOI: 10.2307/2226317.

ROSSER, J. Barkley, Jr. On the complexities of complex economic dynamics. Journal of Economic Perspectives, v. 13, n. 4, p. 169-192, 1999. DOI: 10.1257/jep.13.4.169.

ROSSER, J. Barkley, Jr. Computational and dynamic complexity in economics. In: ROSSER, J. Barkley, Jr. (Ed.). Handbook of research on complexity. Edward Elgar Publishing, 2009. n. 3625.

ROSSER, J. Barkley, Jr. Emergence and complexity in Austrian economics. Journal of Economic Behavior \& Organization, v. 84, n. 3, Dec. 2012.

ROSSER, J. Barkley, Jr. The complex evolution of Duncan Foley as a Complexity Economist. In: TAYLOR, Lance; REZAI, Armon; MICHL, Thomas (Ed.). Social fairness and economics: economic essays in the spirit of Duncan Foley. New York: Routledge, 2013, p. 42-52.

ROSSER, J. Barkley, Jr.; ROSSER, Marina. The evolution of behavioural institutional complexity. In: ARUKA, Yuji; KIRMAN, Alan (Org.). Economic foundations for social complexity science. Sept. 2017, p. 67-88. DOI: $10.1007 / 978-981-10-5705-2 \_4$. 
André Roncaglia de Carvalho, Fernanda Graziella Cardoso

ROSTOW, Walt. As etapas do desenvolvimento econômico. Rio de Janeiro: Zahar, 1974.

RUTHERFORD, M. What is wrong with the new institutional economics (and what is still wrong with the old)? Review of Political Economy, p. 299-318, Nov. 1989.

SETTERFIELD, Mark. A model of institutional hysteresis. Journal of Economic Issues, v. 27, n. 3, p. 755-774, 1993.

VELUPILLAI, K. Vela. Computable economics. Oxford: Oxford University Press, 2000.

VELUPILLAI, K. Vela. A computable economist's perspective on computational complexity. In:

ROSSER, J. B., Jr. (Ed.). Handbook of complexity research. Cheltenham: Edward Elgar, 2009. 